\title{
Lenguajes del poder. Cegueras de los maestros ${ }^{1}$
}

\author{
Maritza Córdoba Calvo ${ }^{2}$, Pilar Magally Mosquera Erazo ${ }^{3}$ \\ Oscar Arturo Restrepo Guerrero ${ }^{4}$, Yeisit Verónica Sabogal Londoño ${ }^{5}$ \\ Nelly Erazo Valencia ${ }^{6}$, Miguel Alberto González González ${ }^{7}$
}

\begin{abstract}
Resumen
En el presente documento se desarrolla un análisis de la ceguera como metáfora entendiéndola como una manifestación compleja y multicausada presente en el ejercicio de maestro, es una aproximación hacia al protagonismo de este concepto y su incidencia en la escuela. Durante el proceso investigativo se intenta develar las estructuras de poder que convergen en el escenario educativo, en particular reconociendo el protagonismo del Estado en su capacidad de reproducir relaciones de producción y control a través de instituciones educativas bajo las apariencias de bienestar, progreso, desarrollo, ciencia, principios utilitaristas que se han incorporado en el maestro al desconocer los mecanismo de dominación y poder ejercidos a través de la instrumentalización, jerarquización y división social que posteriormente los maestros ejercen en la aulas de clase dando cuenta desde su propio devenir histórico.

Para la realización de este recorrido se ha tomado las autobiografías o historias de vida de cada uno de los integrantes posibilitándole de esta forma espacios de intervención investigativa cualitativos, en esta instancia, pretendemos incorporar algunas reflexiones que contribuyan a determinar la sintomatología de la ceguera más allá de su percepción como discapacidad visual y del efecto de su presencia en el maestro en particular y en la educación, en general, a propósito de la cuestión de la diferencia
\end{abstract}

1 Recibido: julio 20 de 2013. Aceptado: 24 de marzo de 2014.

2 Maritza Córdoba Calvo. Normalista Superior de la Institución Educativa Escuela Normal Superior de Popayán. Licenciada en Educación Básica con énfasis en Lengua Castellana e Inglés de la Universidad del Cauca. Docente en la Institución Educativa Técnico Industrial de Popayán. Correo electrónico: maritzacordobacalvo@hotmail.com

3 Pilar Magally Mosquera Erazo. Administradora de empresas de la Universidad del Cauca. Docente de Centro Educativo la Arroyuela sede El Diamante. Correo electrónico: pilmagmosquera@gmail.com

4 Oscar A. Restrepo Guerrero. Geógrafo de la Universidad del Cauca. Docente de la Institución Educativa Agrícola de Argelia. Correo electrónico: razorrestrepo@gmail.com

5 Yeisit Verónica Sabogal Londoño. Psicóloga de la Fundación Universitaria de Popayán. Docente en la Institución Educativa Gabriela Mistral de Popayán. Correo electrónico: verosab1609@yahoo.com.mx

6 Nelly Erazo Valencia. Licenciada en Etnoeducación. Docente en Centro Educativo Michinchal sede Michinchal. Correo electrónico: nellyerazov@hotmail.com

7 Miguel Alberto González González. Director de la investigación: Lenguajes del poder ¿Lenguajes que nos piensan?, asesor y director de la tesis de maestría y del presente artículo devenido de la investigación. $\mathrm{PhD}$ en Conocimiento y Cultura en América Latina -IPECAL-México; PhD en Ciencias de la Educación Universidad Tecnológica de Pereira. Docente e Integrante equipo investigativo, Universidad de Manizales; Docente e investigador Universidad Católica de Pereira. Correo electrónico: mgcaronte@me.com 
Para la realización de este recorrido se ha tomado las autobiografías o historias de vida de cada uno de los integrantes posibilitándole de esta forma espacios de intervención investigativa cualitativos, en esta instancia, pretendemos incorporar algunas reflexiones que contribuyan a determinar la sintomatología de la ceguera más allá de su percepción como discapacidad visual y del efecto de su presencia en el maestro en particular y en la educación en general, a propósito de la cuestión de la diferencia.

Palabras claves: ceguera, educación, maestro, memoria, poder y modernidad.

\section{Abstract \\ Languages of power. Blindness of teachers}

In this paper, a blindness analysis is developed as a metaphor, understanding it as a complex and multi- caused manifestation present in the teaching exercise, it is closeness towards the importance of this concept and its influence in school. During the research process, it is intended to reveal the power structures that converge in the school context by recognizing, specially, the state importance about its ability of reproducing production and control relationships through schools under the appearance of wellbeing, progress, development and science; utilitarian principles that have been incorporated themselves in teachers by ignoring the rule and power mechanism exercised through the exploitation, classification and social division which teachers exercise afterwards in classrooms by accounting for their own historical future.

To carry out this process, some autobiographies or lives stories have been taken into account to make qualitative research interventions possible. We try to incorporate some reflections that help to determine both the blindness symptoms beyond the visual disability perception and the effect of its presence particularly in teachers as well as in education, generally, in relation to the difference matter.

Key words: blindness, education, teachers, memory, power and modernity.

\section{Presentación}

Está investigación hace parte del Macro proyecto Lenguajes del poder. Lenguajes que nos piensan. En su interés por "encontrar el proceso del orden y el desorden que legitiman los lenguajes del poder desde la educación, en este siglo XXI", Miguel Alberto González González (2010) como investigador principal concibe el proceso investigativo, como un acto de responsabilidad consigo mismo y con la humanidad pero también como un riesgo, como una aventura; como una oportunidad para conocer y para construir conocimiento.
Esta construcción de conocimiento surge bajo la necesidad de significar en las cegueras-desde el campo de la educación- no como una patología sino como una palabra dotada de gran sentido simbólico para reflexionar sobre El Estado y las Instituciones (particularmente la Educativa), las familias; y las relaciones de control que ejercen sobre nuestras vidas. Para lograr este propósito hemos dado muerte a nuestros ojos para reconocernos a partir la experiencia y lo sensible. También se invita a buscar en la memoria del tacto una forma de recuperar nuestra humanidad. 
Esperamos que a partir de la lectura de este documento podamos aportar desde la alegoría y las relaciones de poder una nueva representación de la palabra ceguera. Para que ya no solo se conciba como una dolencia o enfermedad, sino como una excusa para reflexionar este mundo tan lleno de lenguajes de poder.

\section{La ceguera una experiencia de sensibilidad}

\subsection{La ceguera, un horizonte por descubrir}

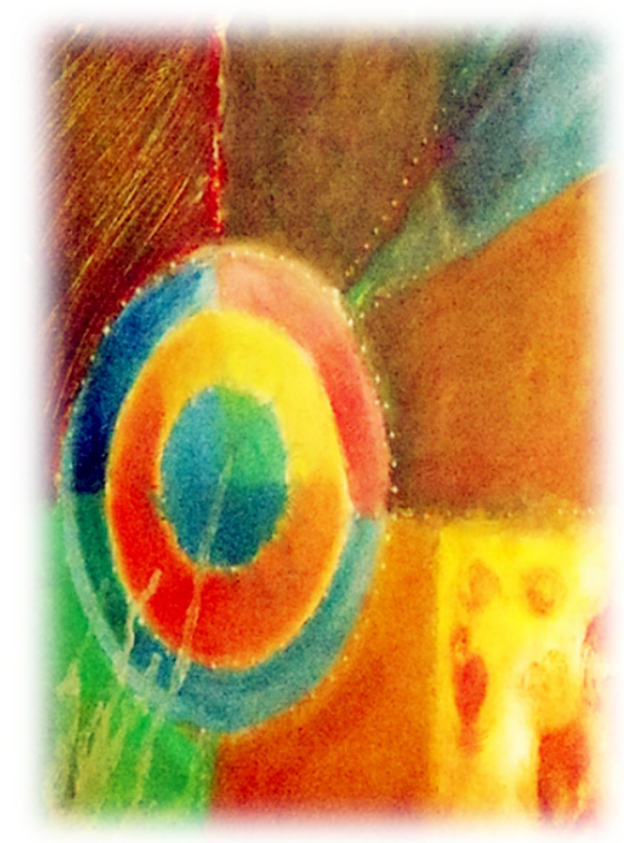

Cegueras de los maestros

Óleo sobre lienzo. 2012

Comprender la vida misma como un tejido de relaciones que se despliegan y penetran desde los lenguajes de poder no es una tarea fácil. Por eso, nos hemos valido de la metáfora ceguera para reflexionar sobre algunos episodios de nuestras vidas y su relación con la historia global. Además estamos convencidos que la ceguera es una forma de ser y estar en el mundo a partir de las experiencias que nos otorga la memoria.

Este estudio cobra importancia en la medida en que resignifica el valor de conceptos como la ceguera, ya que es un estado por descubrir y pensar, así lo expresaba Borges en uno de sus versos: "Demócrito de Abdera se arrancó los ojos para pensar". Nuestro propósito es comprender la ceguera como una metáfora para cuestionar y analizar las relaciones de poder del Estado Moderno, el Capital Cultural y el Trabajo en la vida cotidiana. Queremos que las personas que lean nuestras voces sean capaces de cuestionarse y problematizar su existencia.

De ahí que consideremos a la ceguera como un símbolo que permite descubrir otras realidades, otras percepciones de la vida y otras formas de estar en el mundo. Es así, como en este documento usted encontrará en la ceguera un instrumento para expandir sus horizontes desde la memoria, las historias de vida y sus propias cegueras.

Por tanto, hemos planteado un interrogante para analizar nuestras cegueras, expresado a continuación ¿Cuáles son las cegueras de los maestros de las instituciones educativas: Agrícola de Argelia, Técnico Industrial de Popayán y Gabriela Mistral de Popayán, y de los centros educativos: la Arroyuela sede El Diamante y Michinchal sede Michinchal, año 2012-2013?

\subsection{Percepciones de algunos autores sobre la ceguera}

Recordemos que el mundo no es visual es multisensorial, es por eso que requerimos explorar otras experiencias y conceptos sobre la ceguera para estimular la escritura de este documento. De esta manera se retoman algunas percepciones que enriquecen y nos permiten enfocar este estudio hacia nuevos aprendizajes en relación con nuestras situaciones personales y los lenguajes de poder. 
En primer lugar nos referiremos a $\mathrm{Ca}$ rolina Britt Backman Sepúlveda por un capítulo de su documento "Fotógrafos ciegos: percepción en la invidencia y la desmitificación de la pureza visual". En el capítulo uno, Percepciones sobre y desde la ceguera, ella analiza la procedencia de algunos prejuicios sobre la ceguera y la forma en que se ha mitificado a los ciegos, su percepción, sus habilidades cognitivas y perceptivas. También resalta la importancia que se da a la visión actualmente, dejando la idea de que aquel que no ve está desahuciado. Sin embargo se destaca el hecho de que la visión no es automática, se construye y se debe aprender a ver "Dar sentido al mundo percibido por la vista" porque la visión es aprendida y depende de otros sentidos para establecer conexiones, sobre todo del tacto con el cual se "Discierne formas y distingue el espacio en perspectiva, a través de la experiencia y los recuerdos". Ahora bien, nuestro propósito, al igual que Carolina Britt, es otorgar otras percepciones sobre la ceguera y su relación con varios aspectos de nuestras vidas. Para conseguirlo otorgaremos a los lectores de este documento conceptos que surgen a partir de nuestra cotidianidad y de la memoria de nuestros recuerdos.

Otro documento que hace referencia a la temática que estamos abordando es "Ensayo sobre la Ceguera" de José Saramago. En esta novela ensayo se narra un extraño suceso en donde los habitantes de una ciudad quedan ciegos repentinamente. Sólo una persona no es afectada por esta ceguera blanca, y es ella la encargada de dar cuenta de cuál es la condición humana cuando ha sido privado del sentido de la vista y hasta donde es capaz de descender en su dignidad por falta de él. Paradójicamente de la misma forma que llegó la ceguera se va y afecta a aquella persona que nunca estuvo ciega gracias a los sentimientos de amor y de solidaridad que poseía.

Es necesario resaltar que Saramago a través de los personajes y situaciones de su obra hace fuertes críticas al sistema, la religión y lo medios de comunicación, catalogándolos como factores causantes de la ceguera en el ser humano. Con su ensayo se reconoce la importancia de la metáfora ceguera no solo para construir narraciones de tipo literario sino de gran carga crítica. Saramago expuso su pensamiento de las sociedades actuales en una novela. Los maestros, también podemos exponer a partir de narrativas autobiografías lo que no se ve a causa factores externos, en nuestro caso, a raíz del capital cultural, el trabajo, el poder del Estado y las instituciones.

Para finalizar, el colombiano Miguel Alberto González González en su libro "Umbrales de indolencia. Educación sombría y justicia indiferente", publicado en el 2010 hace también referencia a la ceguera. En éste texto se cuestiona la educación latinoamericana, por motivo del bicentenario de la independencia, haciendo un despliegue de relaciones entre el tiempo, la historia y los lenguajes del poder, a lo cual él denomina "akairós o destiempo educativo". Dado que refiere que uno de los grandes problemas de América Latina, desde la conquista y la colonización, ha sido el sometimiento y la dominación. Además ratifica que el olvido y la ausencia de memoria histórica en los latinoamericanos les han hecho ciegos, sordos, silenciosos y conformistas ante las problemáticas actuales.

Ante este complejo panorama, el autor, otorga gran valor y esperanza sobre los maestros, de quienes dice: "no son de oído duro ni de imaginación roída" (González, $2010,11)$. En otras palabras, él asegura que los maestros son los intelectuales que podrán construir una realidad educativa contraria a la que se ha impuesto, y de esta manera se podrá conseguir una verdadera emancipación en los países latinos. Pero para conseguir éste propósito, afirma, que primero deberán aprender a afinar la mirada para identificar y comprender los lenguajes que controlan nuestras vidas. 


\section{Objetivos}

Dentro del marco de este proyecto investigativo se planteó un objetivo general el cual es: Sintetizar las cegueras de los maestros de las instituciones educativas: Agrícola de Argelia, Técnico Industrial de Popayán y Gabriela Mistral de Popayán, y de los centros educativos: la Arroyuela sede El Diamante y Michinchal sede Michinchal, año 2012-2013. Y también tres específicos los cuales orientaron este proceso, estos son: Propiciar estados y espacios de reflexión a partir de la metáfora ceguera; Identificar las manifestaciones de ceguera en los maestros a partir de análisis autobiográficos: y Reconocer las cegueras más frecuentes de los maestros en su quehacer pedagógico.

\section{Las voces de los teóricos}

\section{Ceguera: metáfora y reflexión}

La ceguera puede estudiarse desde un amplio espectro de significados científicos, sociales, psicológicos, físicos, emocionales, entre otros. Pero el estudio que aquí nos convoca sobre la ceguera de los maestros se da desde la metáfora que ésta representa para los Lenguajes del Poder. La ceguera, nos permitirá reflexionar, desde adentro, lo que esconde la memoria de nuestras vidas. Y así conocer los factores externos que hasta el momento han movilizado nuestro pensar, sentir y actuar. Ver figura 1.

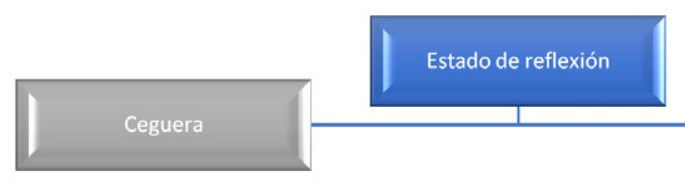

Figura 1. Definición sobre la ceguera

\subsection{El sujeto y el poder}

Hablando de poder, éste es entendido como aquellas formas de dominación (explotación, sujeción y sumisión de la subjetividad) ejercidas a través del tiempo por el hombre que tienen como fin individualizar o totalizar al sujeto. Para Foucault (1991, p. 77) el poder está representado por el Estado que tiene la "(...) Facultad de integrar a los individuos, moldeándolos de otra forma y de someterlos a una serie de patrones muy específicos". Así, el poder se convierte en un conjunto de relaciones que usa como vehículo el lenguaje, un sistema de signos o símbolos, los cuales usamos diariamente no sólo en nuestro quehacer pedagógico sino en todas nuestras relaciones para obtener los objetivos propuestos en todas las instancias.

Nuestro propósito es reflexionar cómo se han incorporado y bajo qué formas se manifiestan esas relaciones de poder y control en nuestra cotidianidad. Esta relación ha sido estudiada por autores como Foucault (1991, p. 51), la relación del ser humano con factores externos da como resultado la "transformación de humanos en sujetos" a las relaciones de producción y racionalización que son provocadas por el Estado. Se cuestiona entonces la forma en la que este tipo de relaciones están asociadas con el poder del Estado Moderno y su incidencia en la vida de cada individuo. El análisis realizado por Foucault describe como históricamente el poder se ha convertido en una enfermedad cuyos mecanismos políticos se transforman bajo los intereses de unos pocos. Estas relaciones de poder no son claras a nuestros

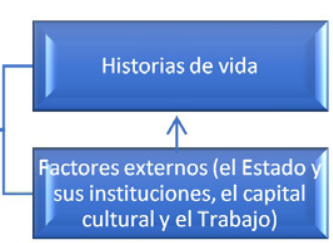

ojos. Recordemos que: "Esta forma de poder se aplica en la inmediata vida cotidiana que categoriza al individuo, lo marca por su propia individualidad, lo adhiere a su propia identidad, le impone una ley de verdad que él debe reconocer y que los otros tienen que reconocer en él. Es una forma de poder que hace a los individuos sujetos.". (Foucault, 1983, p. 60). 
El poder según Foucault se ha presentado históricamente bajo varias formas: dominación, explotación, individualización y en la actualidad bajo las formas de sujeción.

Desde el siglo XVI, se ha perfeccionado una nueva forma de poder político: El Estado. Éste ha usado técnicas de poder como el poder pastoral (individualización de la gente a partir de la forma de salvación) para fijar sus estructuras individualizantes. Sin embargo esa forma fue perdiendo vitalidad. Razón por la cual en el siglo XVIII, una nueva forma de poder se desarrolla de manera objetiva bajo la idea de asegurar a las personas en este mundo. Esta nueva apariencia de la salvación toma el rostro de salud, bienestar, seguridad, educación, higiene, entre otras. Entonces el Estado se convierte en una "matriz moderna de individualización" (Foucault, 1983, p. 65), ligada no sólo a la institución religiosa sino a una variedad de instituciones relacionadas con la educación, la medicina, la familia y el cuerpo social. Ver figura 2.

\subsection{Cegueras modernas}

Existen factores externos como la tecnología, la cultura, el capital cultural y la sociedad que nos construyen -construyen el yo-. Es claro, que estos factores externos están configurados por la relación histórica y utilitaria para disciplinar, someter y modelar el cuerpo, las sensaciones, valores, discursos (...). También es evidente que cada factor no es independiente a la transformación a escala planetaria de las normas, relaciones y representaciones en el hacer, pensar y sentir de cada cultura, en otras palabras depende de los poderes que se manejen desde lo global. Por eso a continuación se hablará del trabajo, la tecnología y el capital cultural como factores externos que inciden en la personalidad de los sujetos. A ese conjunto de factores externos los hemos denominado cegueras modernas (ver Figura 3).

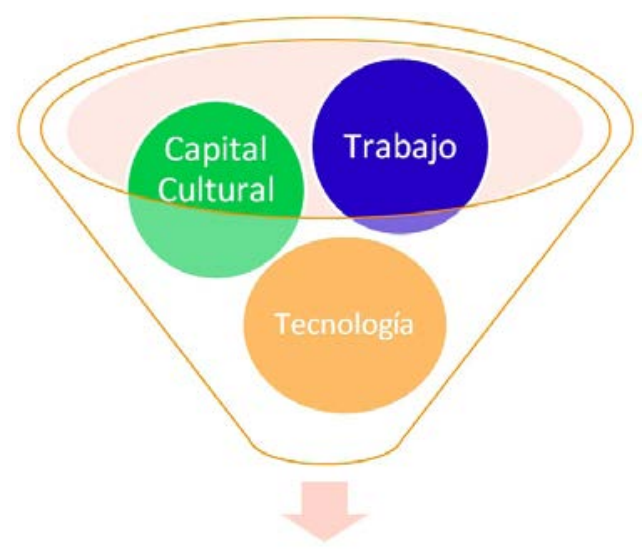

Cegueras Modernas

Figura 3. Cegueras Modernas

El primer factor externo que mencionaremos es el trabajo. Para Guarín (2011) la jerarquización que sustenta el trabajo ha instrumentalizado la vida laboral y

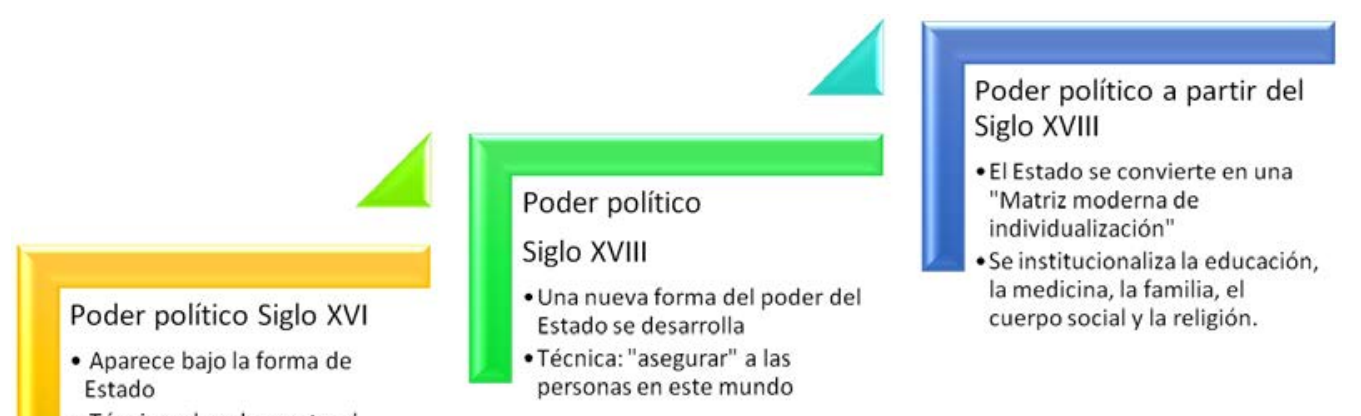

Figura 2. Las formas de Poder según Foucault 
las relaciones humanas, logrando que el vínculo entre la triada sujeto- trabajo y conocimiento sea netamente de utilidad. Asimismo Fromm (s.f) afirma que la sociedad moderna ha hecho del hombre una mercancía, un instrumento de fines económicos, movido por su egoísmo y su insatisfacción constante susceptible a la manipulación de las leyes del mercado donde ningún sector se escapa.

El segundo factor externo al cual nos referiremos es el capital cultural. En cuanto al capital cultural Pierre Bourdieu (s.f), en su texto Los tres estados del capital cultural, describe que las diferencias sociales inciden en el éxito escolar de los educandos. Él plantea que la relación entre las tasas de rendimiento escolar no depende exclusivamente de la inversión educativa y económica. La educación sólo reproduce las estructuras sociales dominantes. Afirma que la educación depende del capital cultural y capital social que la familia invierta. El capital cultural puede existir bajo tres formas: estado incorporado (disposiciones duraderas del organismo (hábitos, tiempos, necesidades), estado objetivado (bienes culturales, libros, cuadros, en resumen un título con valores simbólicos, jurídicos, materiales) y el estado institucionalizado (título escolar) la negación de las prácticas y creencias culturales desde el aula.

El último factor externo al cual se hará referencia es a la tecnología. Guarín (S, f) en su documento sobre la modernidad positiva, refiere que la tecnología, la ciencia y la ilustración se establece como una nueva lógica de auto-afirmación, auto-justificación, auto- legitimación del proyecto moderno. El valor de la tecnología es meramente utilitario, dado que, sus intereses se centran en la productividad de la industria y el trabajo. Al mismo tiempo, lo dispositivos tecnológicos controlan los sentidos, las emociones y experiencias de los individuos, a esta configuración subjetiva Foucault le denomina biopolítica. Se genera así una crisis de principios y valores, pues este mecanismo de poder individualiza y privatiza las relaciones sociales; y se crea así otro vacío político más en la historia de la humanidad.

\section{Recorrido en busca de las cegueras}

Este proyecto se desarrolla en torno a la investigación cualitativa, pues dentro de nuestro trabajo como docentes debemos andar el terreno en el cual vamos a investigar, dado que las particularidades del ejercicio educativo no sólo demandan la construcción de una relación holística entorno a los seres con los que estamos trabajando sino que además define posibles escenarios de interpretación de una realidad construida socialmente, basados en la particularidad devenida por manifestaciones fenomenológicas, ya que al apoyarnos en ella, se potencian nuevas formas de brindar conocimientos a la sociedad, y así poder iniciar la transformación de esa realidad educativa tan sensible a las apariencias o impresiones de nuestros ojos.

El recorrido metodológico de esta búsqueda de las cegueras del maestro se inicia a partir de tomar, como instrumentos investigativos, los relatos de las historias de vida de los maestros Nelly Erazo Valencia (I.E. El Carmelo - Cajibio), Pilar Magally Mosquera Erazo (I.E. El Carmelo Cajibio), Yeisit Veronica Sabogal Londoño (I.E. Gabriela Mistral - Popayán), Maritza Córdoba Calvo (Instituto Técnico Industrial - Popayán) y Oscar Arturo Restrepo Guerrero (I.E. Agrícola - Argelia). Esto con el fin de lograr un análisis, que en un segundo momento, permitirá emerger categorias divergentes y convergentes entre situaciones resignificadoras de momentos historicos en el campo educativo, social y cultural abriendo la posibilidad de que estos permitan describir, interpretar y analizar sus realidades con el fin de comprenderlas e intervenir desde diferentes lenguajes. El proceso de las autobiografías o historias de vida puntualiza en los 
contextos particulares como manifestación de una macro-estructura social:

"Las historias de vida están formadas por relatos que se producen con una intención: elaborar y transmitir una memoria, personal o colectiva, que hace referencia a las formas de vida de una comunidad en un período histórico concreto; y se generan a petición de un investigador. Los relatos que de ella surjan se encuentran marcados por esta experiencia conversacional no espontánea. En principio, las historias de vida no preexisten a este proceso, se producen en él. Se van haciendo a medida que la investigación avanza según sus objetivos, sus hallazgos y sus límites" (Marinas \& Santamarina 1993, citado por Plano \& Querzoli, 2003, p. 3).

Con el objetivo de dar cuenta sobre el significado de la metáfora ceguera de los maestros en el campo educativo se han dado los siguientes pasos, aquí están representados:

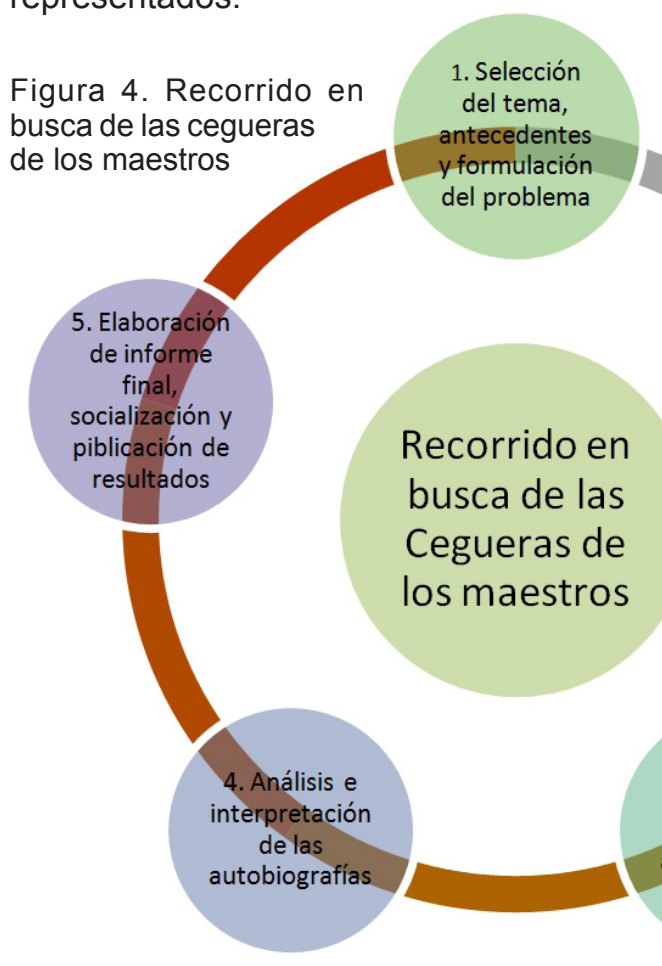

3. Elaboración de autobiografías

\section{Hallazgos}

"La tarea del análisis consiste, en esa mezcla de informaciones, extraer la manera como la persona se ve en su relación con el mundo, la interpretación que da a su experiencia global de vida, la verdad vivida, para decirlo de esta manera, que subyace al conjunto de su cotidianidad" (Morín, 1974 citado por Pierre 2004, p. 79). Como se ha expresado con anterioridad uno de nuestros objetivos fue sintetizar las cegueras de los maestros a partir de nuestras propias historias de vida. Para conseguirlo, cada coinvestigador escribió su autobiografía, luego, se extrajeron fragmentos relacionados con los lenguajes de poder. Estos datos nos permitieron ir delimitando nuestro estudio. En ese momento, nos centramos en analizar las informaciones recogidas, con el fundamento teórico y conceptual de autores como Foucault, Freire, Guarín, Bourdieu; y las notas de las conversaciones sostenidas durante los seminarios de investigación con Miguel Alberto González González. Entonces comenzamos a agrupar los datos teniendo en cuenta sus semejanzas; y diferencias. Después de leer y releer las informaciones recogidas, las categorías que surgieron fueron: educación,

2. Definición y fundamentación teórica el trabajo, la tecnología y el poder del Estado. De esta manera se pudo reconstruir experiencias que se repetían en diferentes contextos; al mismo tiempo en que se identificaban sus causas. La generalización de los datos que se obtuvieron a partir de nuestras autobiografías nos permitió dar varias interpretaciones sobre la vida cotidiana desde los lenguajes de poder. 


\subsection{Cegueras convergentes}

La categoría central en esta investigación la hemos denominado cegueras hereditarias donde se discute la educación como una herencia, una fortuna o una trampa. Para ello hemos recurrido a los recuerdos que nuestra memoria guarda para construir lo que verdaderamente ha sido la educación en nuestras instituciones educativas y en nuestras familias plasmando esas impresiones "huellas" dejadas por nuestros profesores y padres en nuestras vidas. Aquella educación que hemos sentido desde adentro, es decir desde el campo de lo sensible.

En primera instancia identificamos que tenemos en común los siguientes aspectos:

El tipo de relación dada con nuestros padres y maestros. Constituida principalmente por una relación jerárquica donde unos ocupan una posición alta, de dominio y de autoridad (padres, jefes, maestros); mientras que la otra parte está subordinada a la expectativa de cumplir, obedecer las órdenes y deseos de quienes detentan el poder hijos, estudiantes, empleados. Relación que minimiza a los subordinados y satisface los intereses de los opresores.

También cabe resaltar las técnicas de sumisión utilizadas tanto en los hogares como en las escuelas, estas tienen que ver con la intención por parte de los adultos o de quienes ejercen autoridad de mantener siempre el control utilizando gritos, regaños, castigos, silenciando, amenazando, dando malos tratos, emitiendo prohibiciones y en caso de la escuela la asimilación obligada de conocimientos en otras palabras hacer uso de la "buena memoria".

Encontramos el miedo y el castigo como formas de control cuyo fin es disciplinar, someter, modelar el cuerpo y las emociones. Las cuales se reproducen aún en la actualidad. Estas formas de control es lo que nosotros hemos denominado apariencias incorporadas, debido que a través del cuerpo se ha logrado incidir en la lectura individual y colectiva de lo que se debe hacer, pensar y sentir. Donde se nos incorporó la imagen "se nos implantó el chip" de un mundo que sólo se puede abordar a partir del poder intelectual (conocimiento). El cual se determina por medio de un sistema comprendido en el estudio o asimilación de asignaturas específicas, la obtención de títulos académicos, la acumulación desmedida de grandes sumas de dinero, de bienes, de servicios y de aparatos tecnológicos. Generando unos efectos que atentan contra la libertad y autonomía producto de las relaciones de poder actuales (ver Figura 5).

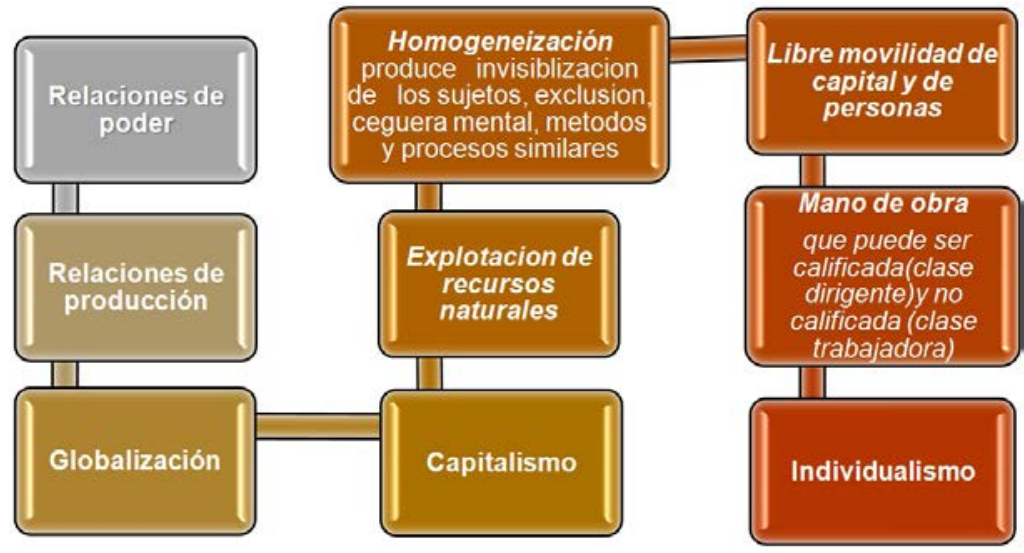

Figura 5. Las relaciones de poder en la actualidad

Estudiar entonces se torna en una actividad económica muy importante, se realiza no con la visión griega de llegar a ser adulto, estado donde se obtiene autonomía y libertad, si no con el fin de acceder 
a un sistema cada vez más competitivo. Luego para ello se condicionan los espacios (escuelas, universidades, centros de formación) y los tiempos (grados, semestres, niveles, ciclos) bajo la promesa de obtener títulos que garanticen beneficios materiales y simbólicos gracias a la configuración de Instituciones y discursos sociales que la mayoría de veces no suple las necesidades y expectativas de las personas, porque sin darnos cuenta estamos inmersos en un modelo de producción y de dominación global, el cual repetimos continuamente logrando instrumentalizarnos, jerarquizarnos y dividirnos socialmente; deshumanizándonos cada día más. Puesto que la educación no se ve como un acto político para generar autonomía, cambio, transformación y liberación de los sujetos sino como una mercancía más en el mercado. Aspecto que ha permeado nuestras prácticas educativas, laborares y familiares.

Esa visión de mundo centrada en el "dinero y en los bienes" ha perdurado por mucho tiempo en nuestra cultura, así por ejemplo los maestros estudian con el objetivo de aumentar sus ingresos, mejorar su posición social y su calidad de vida no para adquirir nuevas herramientas que dinamicen su quehacer pedagógico. Pensando siempre individual y no colectivamente. Aspecto característico del modelo de dominación imperante.

\subsection{Cegueras divergentes}

Cegueras divergentes es una categoría en la cual se reflexiona sobre la proximidad de los sujetos históricos, críticos del sistema y de las estructuras globales que constituyen nuestros comportamientos, significados, representaciones. Es evidente que en cada historia de vida narrada hay un valor simbólico que se define por el poder que el Estado, el capital cultural, la tecnología y la modernidad ejerce en nuestros actos.

A continuación se sintetizan las categorías que emergen a partir del análisis de nuestras propias autobiografías:

\section{Crisis y homogeneización ¿Qué hay bajo tus ojos?}

Según el panorama mundial en esta "aldea global" hay un estado de emergencia que bajo el lenguaje dominante del capitalismo se conoce como "crisis" .Esa crisis abarca todos los sistemas; los cuales deben ser modificados para lograr darles solución y al parecer la alternativa escogida fue la de fundamentar toda la existencia humana en la generación de capital, tecnologías, bienes y servicios para satisfacer las necesidades del hombre. En palabras de Foucault el hombre trabaja, es decir, es un sujeto productivo, lo cual demanda establecer relaciones de producción y de significación reguladas por unas relaciones de poder encaminadas a la explotación y a la homogeneización de gustos, comportamientos, leyes y costumbres de manera universal. En seguida, daremos un vistazo a aquellas relaciones de poder "modelación" características de nuestra cultura gracias a la reproducción continua de los modelos establecidos por las clases dominantes.

\section{Percepciones en serie}

Producción en serie, hace referencia a las grandes cantidades de bienes, servicios y profesionales. Esta producción se caracteriza por utilizar diseños estandarizados para que todo lo producido sea igual y no haya ninguna diferencia entre ellos y de esta manera poderlos distribuir en cualquier parte del mundo.

El campo educativo también ha sido permeado, por esta medida se diseñan metodologías, temáticas, estándares, se aplican modelos pedagógicos y se especializa (fracciona) el conocimiento como lo explica Morín (2001) "La educación del futuro se ve confrontada a este problema universal, ya que existe una inadecuación cada vez más amplia, profunda y grave entre, por un lado, nuestros saberes desarticulados, parcelados y compartimentados $y$, por el otro, las realidades o problemas cada vez más poli disciplinarios, transversales, multidimensionales, 
transnacionales, globales, planetarios (...)" porque prometen ser un "buen molde" que garantizarán el éxito en el campo laboral, aunque no sea de igual forma en las relaciones sentimentales, familiares o con el entorno (naturaleza). Ya que no estamos pensando la condición humana de ser diversos inhibiendo la autonomía, la búsqueda del conocimiento y de la verdad, todo esto lo podemos resumir en una especie de "ceguera mental" donde los individuos perciben correctamente las imágenes, pero son incapaces de darles un sentido. Ver cuadro 6 .

Luego, lo que se requiere para que nuestros países latinoamericanos cambien y ya no nos reconozcamos como países subdesarrollados o emergentes (categoría producto de los lenguajes del poder) es una educación liberadora, de concienciación de la condición social del individuo. Como se muestra en la figura 7.

\section{Cegueras al trabajo}

A propósito del trabajo existen variedad de refranes al respecto, como por ejemplo: "A quien trabaja no le falta su paga", "El trabajo y la economía son la mejor lotería", "Al que madruga Dios le ayuda". Social y culturalmente el

Daño interior

sentimientos de culpa, autocompasiòn. perdida de confianza

CEGUERA MENTAL

Perdida del dialogo y del discurso Perdida de la creatividad e innovacion
Figura 6. Ceguera mental y sus efectos

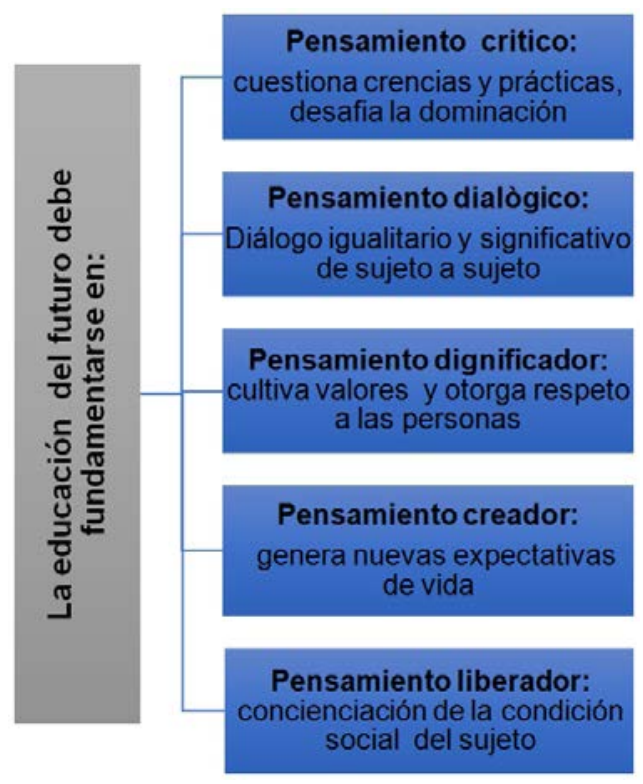

Figura 7. Fundamentos Reales de la Educación trabajo se considera un privilegio, otorgando infinidad de cualidades moralistas y económicas, como se hace evidente en los refranes. Retomando algunos conceptos de Foucault podría decirse que el trabajo usa el lenguaje para incorporarse en nuestras vidas al mismo tiempo en que "asegura a las personas en este mundo", ejerciendo cierto poder y control en la vida de cada individuo.

El poder y control que ejerce el trabajo, a través del lenguaje, no se percibe a simple vista. Razón por la cual este factor se tiene que analizar desde otro ángulo, desde los registros en nuestra memoria. Es así, como a partir de nuestras propias experiencias se ha concluido que el trabajo se incorpora bajo la forma de necesidad, como se leerá a continuación: "A pesar del dolor que mi mamá sentía por dejarnos tuvo que aceptar el trabajo como profesora en una lejana escuela de la Sierra-Cauca. Mi papá también consiguió trabajo (...) Mamá, papá y Jineth tuvieron que irse, nosotros, tuvimos que quedarnos solos." (Córdoba, 2012). Resulta paradójico que una profesora tenga que separarse de sus propios hijos para enseñar y cuidar de otros niños, sólo por intereses económicos. Cuando el tra- 
bajo se instaura bajo estas circunstancias hace que todo lo cercano y amado se aleje, provocando dolor y sufrimiento. Este tipo de separaciones hacen que las personas se transformen en sujetos de producción, y por lo tanto del poder. Entonces la relación sujeto-trabajo, configura y controla las subjetividades de quienes están involucrados, en este caso del empleado y su familia. Ante esta visión oculta sobre el trabajo habría que agudizar los sentidos y reconocer que muchas experiencias en nuestras vidas fueron provocadas por lenguajes, valores y representaciones objetivas y utilitarias. Todo lo dicho hasta el momento se sintetiza en la siguiente figura:

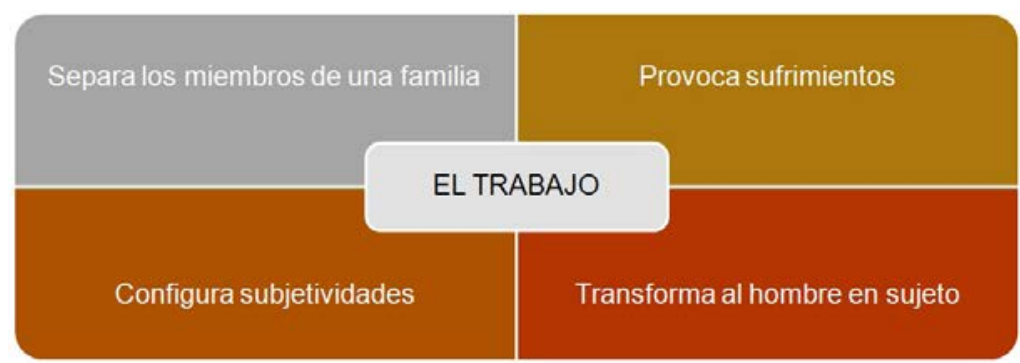

Figura 8. El trabajo: una visión oculta

\section{Cegueras al capital cultural}

Las relaciones amorosas también dependen de jerarquizaciones que están mediatizadas por el capital cultural. El capital cultural que tenga una persona puede generar conflictos en las emociones y formas de actuar frente a lo convencional: "Tuve que ocultar esta relación a mi familia porque me daba vergüenza decir que salía con una persona que aún no terminaba la secundaria" (Córdoba, 2012). Se puede interpretar que el estado institucionalizado otorga un valor simbólico jurídicamente y a la vez emocionalmente. Limitando las relaciones amorosas dado que el hecho de no tener titulaciones escolares no satisface las expectativas culturales. Se podría decir entonces que hay nuevas formas de noviazgos o relaciones amorosas las cuales se determinan según el capital cultural que los enamorados posean. En otras palabras, un título escolar es garantía de estabilidad laboral, económica, y hoy en día también sentimental.

\section{Cegueras tecnológicas}

"La vida tecnológica está asociada con la influencia en la comunicación" Monteagudo (2013). Las nuevas tecnologías de la información y la comunicación (TICS) como la telefonía móvil, el internet, los correos electrónicos, y otros, han modificado la organización social y cultural en el planeta. De manera que se han transformado las relaciones y representaciones en el hacer, pensar y sentir: "Compre una web cam para verlo todos los dias por Skype. Así conocí a su familia y la relación se hizo más llevadera" (Córdoba, 2012). Las tecnologías de la comunicación según Castro (2004) permiten un acercamiento entre sujetos rompiendo así con espacios geográficos que definen una cultura. Y a la vez transforma las formas convencionales de construcción social del tiempo y espacio. Entonces la relaciones ya no son iguales a las de hace 10 años: "Nuestra relación trascurrió así por dos años: viéndonos por Skype, hablando por celular y viajando cada mes, él a Popayán y yo a Bogotá" (Córdoba, 2012).

Hoy el poder de las tecnologías ha conquistado no solo espacios geográficos, sino también las condiciones psicológicas y de placer. Las tecnologías se incorporan en nuestras vidas sin importar la edad o el género. En las últimas décadas el consumo social de entretenimiento como la tv se hace frecuente en las familias y particularmente en los niños: "Así que después de llegar del colegio y terminar las tareas veía televisión, jugaba con mi hermano menor al escondite o al Súper Nintendo, dentro de la casa" (Córdoba, 
2012). En estos tiempos globalizados las tecnologías tienen un valor simbólico en la medida que se piensen en relación con la diversión y placer.

\section{Cegueras a la diversidad cultural y al poder}

En relación a la categoría divergente ceguera a la diversidad cultural queda implícito que la adopción por el sujeto moderno de los instrumentales ideológicos son principios necesarios para el andamiaje mismo del poder dominante, el cual, al ser la expresión del ejercicio autócrata capitalista, impone su fuerza coactiva de tal manera que sugiere hoy al maestro ajustarse a un ideal urbano-competitivo-tecnológico como elemento esencial de vida. Esta forma de pensar-actuar está basada en legitimar la inteligencia personal y laboral desde lo comúnmente aceptado como necesario para ser competitivo y tomar decisiones con criterio globalizador, segmentando la innovación desde el saber- hacer instrumental de manera que sea eficaz para transformar rápidamente en cultura urbana las expresiones diversas del entorno. De esta forma se adopta un conjunto de sincronías que automáticamente dejan en un apartado de oscuridad a lo que se aleje de este principio, llevándolo consciente e inconscientemente, a cegarse ante su misma realidad situada lo que ayuda a potenciar imaginarios inmóviles en el ejercicio pedagógico e imposibilita entender los procesos de multiculturalidad e interculturalidad que se inscriben en el aula.

A partir de tomar la categoría convergente cegueras al poder en la que se devela la presencia del mismo en el acto pedagógico, se camina por senderos reflexivos que abren la posibilidad de entender los lenguajes que este emplea para posicionarse de una manera que automatiza el desarrollo del día a día construido en procura del saber horizontal, bajo unos roles de pasividad que minimizan los espacios de criticidad. Esta categoría permite el entender que un futuro es posible cuando el maestro converge en su disposición a dar luz a sus cegueras realzando el sentido colectivo elevándolo a una expresión demandante de un juicio acorde a una relación espacio tiempo siendo esto propiciador del repensar el concepto educativo lo que permitirá darle eco a voces que históricamente esperan un acercamiento a su existencia, siempre con la precaución de saber alejarse de postulados ideológicos utilitaristas pues son estos que al disfrazarse de vanguardia distraen del verdadero rostro del poder dominante. El relato autobiográfico convocado en esta investigación devela al maestro como el principal actor educativo que está en el ejercicio de reconocer cómo y por qué el devenir de la escuela se enfrenta a la ultranza del modelo de expoliación económica, social y cultural homogeneizante, solo incluyente bajo la polaridad de ser recurso valioso para la incesante necesidad de crear plusvalía.

Descubrir las cegueras de los maestros puede ser hoy uno de los discursos centrales de la modernidad, pues como concepto se identifica por ser un proceso multidimensional cuya afectación en los escenarios de vida permea a los actores educativos seduciéndolos a trasgredir la escuela como la estructura diacrónica de poder, para partir del propio relato como tensión al poder en su relación con la movilidad social, por ello, dentro de esta corriente se asume que la educación no se agota en el diálogo con el saber sino que exige la vivencia y la construcción de experiencias colectivas que contribuyan a la transformación social. Es así como dentro de la intencionalidad de esta investigación quedan planteadas necesidades pedagógicas, socioeconómicas e ideológicas como fórmula en la potenciación de sujetos críticos como baluarte ante los lenguajes del poder dominante. En este marco, las acciones colectivas realizadas, se constituyen en escenarios propicios para la puesta en escena de los discursos y prácticas que se promueven en los procesos pedagógicos. Esa es la apuesta por una nueva educación. Es educar la educación. 


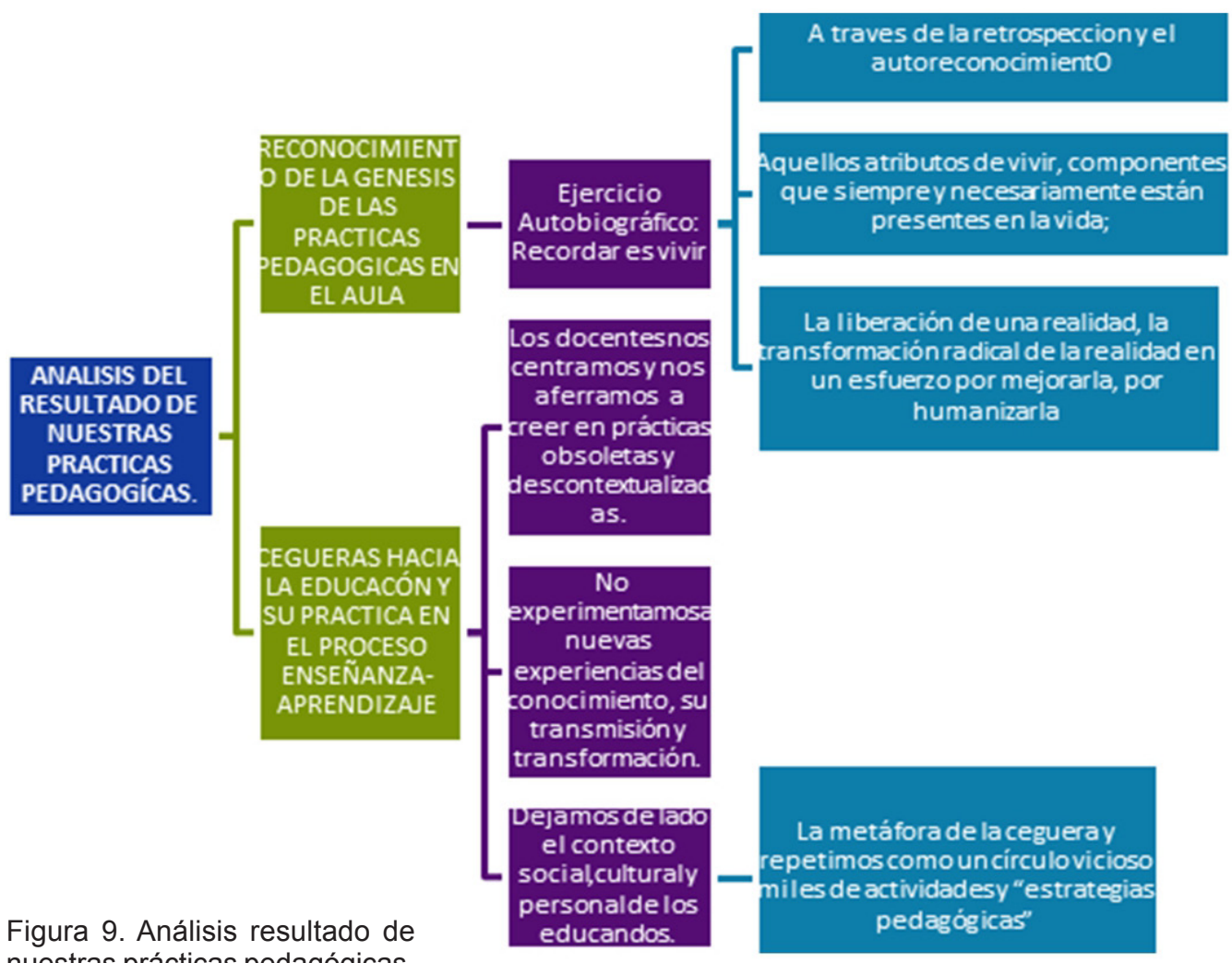

nuestras prácticas pedagógicas.

\section{Matriz de cegueras divergentes}

Por último, en la siguiente matriz se describe las categorías divergentes que emergieron a partir de la interpretación que cada investigador dio a sus propias autobiografías en relación a conceptos como el poder, la educación, el trabajo, tecnologías. Para conseguir este propósito se retomaron autores como Freire, Foucault, Zemelman, Guarín, Bourdieu y otros (Ver Matriz de cegueras divergentes siguiente página).

\section{Ser ciego es como no serlo}

La ceguera no es una condición limitante. Por el contrario es una palabra que, desde los lenguajes del poder, se interpretó desde un mundo más reflexivo y metafórico. A partir de la ceguera se pudo percibir que nuestras vidas necesitan ser examinadas por otros sentidos, dado que la vista muchas veces nos presenta imágenes distorsionadas o borrosas sobre la realidad. Así, cobra importancia los registros sonoros, auditivos, táctiles y emocionales que en nuestra memoria se guardan. Es entonces, cuando las experiencias de la vida misma nos permiten tener otra visión sobre la realidad, una realidad que debe cuestionarse, transformarse, ante la objetividad y el razonamiento del mundo moderno. Dado que la única visión de ese mundo, nos ha llenado de creencias, hábitos y posesiones que nos universalizan y al mismo tiempo nos minimizan. En otras palabras, la ceguera no es ausencia de visión, ni tampoco de ojos; la ceguera es propiamente la incapacidad de palpar y analizar aquellos factores externos que nos han privado de nuestra humanidad y de la libertad. 
Matriz de cegueras divergentes

\begin{tabular}{|c|c|c|}
\hline Autobiografías & $\begin{array}{c}\text { Cegueras } \\
\text { divergentes }\end{array}$ & Descripción \\
\hline \multirow{3}{*}{$\begin{array}{l}\text { Maritza } \\
\text { Córdoba }\end{array}$} & Cegueras al trabajo & $\begin{array}{l}\text { En esta categoría se hace una reflexión sobre el trabajo como un mecanismo de } \\
\text { dominación, que con la máscara de dignificar el hombre, realmente lo deshumaniza. } \\
\text { Modelando sus conductas, sentidos, sentimientos y prácticas entorno a la } \\
\text { necesidad de trabajar. En consecuencia los miembros de una familia se separan. } \\
\text { También se habla del capital cultural como una preparación para el trabajo. Ya que } \\
\text { el consumo de bienes culturales como los títulos académicos se han convertido } \\
\text { en un símbolo de estabilidad laboral. } \\
\text { Por último, en esta categoría se retoman autores como Guarín, Bourdieu y Foucault. }\end{array}$ \\
\hline & Cegueras al amor & $\begin{array}{l}\text { En la categoría se desarrolla una reflexión en torno al amor. Se plantea que hoy en } \\
\text { día las relaciones sentimentales dependen del capital cultural que ambos obtengan; } \\
\text { y de la estabilidad laboral. Se retoma nuevamente a Bourdieu }\end{array}$ \\
\hline & $\begin{array}{l}\text { Cegueras a la } \\
\text { tecnología }\end{array}$ & $\begin{array}{l}\text { En esta parte del texto se estudia cómo se modelan las conductas de los sujetos a } \\
\text { partir del consumo de objetos tecnológicos. Se crean entonces nuevas significados } \\
\text { y relaciones con las personas y los objetos. } \\
\text { En este parte del documento se retoman aportes de Foucault y Hernández }\end{array}$ \\
\hline \multirow{5}{*}{$\begin{array}{l}\text { Nelly Erazo } \\
\text { Valencia }\end{array}$} & Recordar es vivir & $\begin{array}{l}\text { En la categoría se hace notorio la comparación entre el libro vivir para contarla } \\
\text { de García Márquez y la autobiografía de la investigadora. También se encuentran } \\
\text { algunas relaciones con conceptos de Foucault sobre las formas del poder. }\end{array}$ \\
\hline & Momentos inolvidables & $\begin{array}{l}\text { Nos transporta a recordar nuestra infancia junto a la familia y como esta ha } \\
\text { cambiado con el paso del tiempo. }\end{array}$ \\
\hline & $\begin{array}{l}\text { La vocación como } \\
\text { parte fundamental de } \\
\text { la vida }\end{array}$ & $\begin{array}{l}\text { Expone la necesaria urgencia de dedicarlos a lo que realmente nos gusta y nos } \\
\text { apasiona. }\end{array}$ \\
\hline & $\begin{array}{l}\text { Hechos que dejan } \\
\text { huella }\end{array}$ & $\begin{array}{l}\text { Demuestra que es de suma importancia tener muy clara nuestra historia y nuestra } \\
\text { realidad para poder avanzar. }\end{array}$ \\
\hline & $\begin{array}{l}\text { Un nuevo despertar y } \\
\text { sueños vividos }\end{array}$ & $\begin{array}{l}\text { Muestra como al indagarnos sobre nosotros mismos, la respuesta y las soluciones } \\
\text { no se hacen esperar y nos conducen a la realización de esa utopía. }\end{array}$ \\
\hline \multirow{3}{*}{$\begin{array}{l}\text { Pilar Magally } \\
\text { Mosquera }\end{array}$} & Percepciones en serie & $\begin{array}{l}\text { Aquí se narra y se analiza situaciones en las cuales la educación no resuelve las } \\
\text { condiciones laborales a las cuales deben enfrentarse las personas. }\end{array}$ \\
\hline & Percepciones táctiles & $\begin{array}{l}\text { En percepciones táctiles se reflexiona sobre alternativas que resinifiquen las } \\
\text { prácticas de los maestros. Para el análisis se retoma a Freire. }\end{array}$ \\
\hline & $\begin{array}{l}\text { Texturas dejadas de } \\
\text { percibir }\end{array}$ & $\begin{array}{l}\text { Expresa como al ser humano potenciar las facultades intelectuales sacrificas otras } \\
\text { como las emocionales, las colectivas y ambientales. }\end{array}$ \\
\hline \multirow{2}{*}{$\begin{array}{l}\text { Oscar Arturo } \\
\text { Restrepo } \\
\text { Guerrero }\end{array}$} & $\begin{array}{l}\text { Ceguera a la } \\
\text { diversidad cultural }\end{array}$ & $\begin{array}{l}\text { En esta categoría se establece cómo la diversidad cultural se muestra en el lenguaje } \\
\text { de las generaciones actuales como una configuración de relaciones distante y } \\
\text { limitante frente al ejercicio de la inclusión, el cual trasiega espacios sociales por } \\
\text { una delgada línea donde la convivencia de cosmovisiones trae juegos de poder } \\
\text { en el mismo escenario educativo. Este escenario de análisis toma a autores como } \\
\text { Guarín y Zemelman. }\end{array}$ \\
\hline & Ceguera al poder & $\begin{array}{l}\text { La categoría muestra al maestro como protagonista fundamental en el proceso } \\
\text { educativo actor educativo y la necesita inherente de reconocer que su devenir se } \\
\text { enfrenta a la ultranza del modelo de expoliación económica, social y cultural de modo } \\
\text { que se camine en procura de trasgredir la escuela como estructura diacrónica de } \\
\text { poder, para tensionarla en su influencia con la movilidad social, y edificar un horizonte } \\
\text { donde el diálogo con el saber contribuya a la transformación social. La presencia } \\
\text { de los conceptos sobre educación de Freire recorre la propuesta de esta categoría. }\end{array}$ \\
\hline $\begin{array}{l}\text { Yeisit Verónica } \\
\text { Sabogal }\end{array}$ & $\begin{array}{l}\text { Recorrido por las } \\
\text { cegueras de mi vida }\end{array}$ & $\begin{array}{l}\text { Este es un recorrido por las cegueras familiares, a la figura paterna, a la realidad, } \\
\text { a los ideales, además como hacemos ciegos a otros. }\end{array}$ \\
\hline
\end{tabular}


Colombia tiene una vena abierta que ha venido sangrando por años, tal vez muchos la hemos visto de manera superficial, pero no con el corazón. En este sentido, encontramos como resultados arrojados por esta investigación que nuestras cegueras se han ido configurando desde el hogar, la escuela, las instituciones a través de modelos políticos, económicos, sociales y religiosos los cuales nos han enseñado a ser ciegos. El mejor consejo que nos pueden dar es: Vea lo que vea, usted no ha visto nada, no sabe nada, no opina nada.

Así por ejemplo encontramos cegueras adquiridas desde la infancia en el seno del hogar que de manera inconsciente o consciente trasladamos en el aula a los estudiantes en el momento de ejercer nuestra labor como maestros en el proceso de enseñanza - aprendizaje. Cegueras que se evidencian en la indiferencia, la injusticia, la violencia, la agresividad, el egoísmo que vemos a diario en las escuelas y en las calles colombianas.

De la misma forma encontramos cegueras al poder, a la diversidad cultural, a la figura paterna, a los ideales; a nivel laboral, cultural, tecnológico y educativo. Todas estas cegueras se acrecientan gracias al proceso de globalización al que estamos abocados, el cual genera exclusión, invisibilizacion de los sujetos, homogeneización, en otras palabras el ocultamiento de la realidad y perdida de una identidad propia, es decir, ceguera mental.

"Ceguera mental" que está marcada por una serie de patrones globales para el progreso y el desarrollo humano, los cuales van afinando el modelo cientista y la lógica capital. Así se crean relaciones de poder que nadie se atreve a develar, simplemente se aceptan como ciertas y se va construyendo sociedad con base en ellas. Toda nuestra vida ha sido construida sobre la elemental apariencia de educarse para trabajar y sostener los discursos que constituyen la organización económica.
Nos hemos olvidado de nuestras propias historias para mantener unas apariencias globales. Lo peor de todo es que así estamos educando a nuestros niños y niñas sin la posibilidad de indagar y de juzgar lo que se les enseña; como dice un viejo proverbio "Todo se lo comen entero" sin digerir, ni contradecir nada, esto en parte porque los colombianos solemos ser muy crédulos o porfiados.

Por otro lado, esta investigación nos arroja como resultado que acceder a una buena educación es literalmente una fortuna, siempre y cuando esta esté encaminada a la transformación, libertad y autonomía de los sujetos. En ese sentido, lo que se requiere realmente es una educación Kairos justo a tiempo, pertinente en el momento y en el lugar que se requiera. Una educación que nos permita construirnos a nosotros mismos, como sujetos y como pueblo. Una educación que nos saque de la pobreza, de la pasividad y de la indiferencia. Una educación que nos permita abrir los ojos a la realidad, haciéndonos sentir, palpar, oír y gustar mucho más allá de las apariencias, que nos saque del estupor y del letargo en que nos hemos sumido. Una educación que ponga fin a esta apología que hemos hecho de la violencia y de la muerte.

Esa educación debe liberarnos de la mentira y del engaño en el que hemos caído a fuerza de escuchar otros lenguajes, aquellos que nos dijeron son países de la periferia y necesitan ser salvados .Es tiempo de empezar a crear y a establecer un nuevo lenguaje como lo expresa Romanos 12: 2 "No os conforméis a este siglo, sino transformaos por medio de la renovación de vuestro entendimiento", Biblia Plenitud (1960) donde la palabra conformarse implica acomodarse a un modelo o diseño exterior. Se requiere de un modelo propio, autóctono que nazca de lo más profundo del corazón de todas, todos y todis que hacen parte de este territorio.

Al igual que Freire buscamos una educación liberadora, crítica y problema- 
tizadora. Sin embargo hay que aceptar que la educación que impartimos desde las familias y desde las Instituciones Educativas solo acelera la incorporación de apariencias o factores externos sobre un mundo que se reduce cada día a lo estructural, lo intelectual, lo tecnológico, lo científico y lo económico. Por eso, lo que se encuentra en cada Institución o Centro Educativo es una reproducción de métodos y de modelos pedagógicos globales para sostener dichas apariencias. A ello hay que sumarle que los maestros utilizan dispositivos como la calificación y el miedo para demostrar su poder y controlar a temprana edad los cuerpos y emociones de los estudiantes. También existe una obsesión por el rendimiento académico porque hay que entregar un producto óptimo acorde con las exigencias de la maquinaria global (saber leer, escribir, memorizar y realizar cálculos). Este sistema autoritario no permite cambios ni la participación de los estudiantes para que cada niño, niña o joven explore su entorno y construya su propio conocimiento a través de la experiencia, por el contrario se hace más énfasis en la teoría que en la práctica. Cumpliendo así, con una labor silenciadora de sueños, esperanzas, ideas, expectativas de vida de los estudiantes. Dando como resultado niños, niñas y jóvenes dañados interiormente que pierden la costumbre de hablar, de asombrarse, de preguntar; con sentimientos de culpa y de autocompasión, que han perdido la confianza en sí mismos y en los demás. Incapaces posteriormente para demostrar comportamientos contrarios a los de la estructura dominante.

Pero surge una luz de esperanza en las nuevas generaciones de maestros que tratan de desprenderse de estas apariencias incorporadas desde lo global, confiamos en que no terminen reproduciendo las practicas utilitarias y de sometimiento que se han mantenido históricamente.

Por último, el sujeto se diluye en el conformismo cotidiano de sobrevivir vendiendo su fuerza de trabajo al infierno terrenal capitalista, a la burocratización de lo denominado como libertad que propicia la banalidad de la estratificación social. La violencia epistémica con que estos relatos emergen y se posicionan en las circunstancias actuales, son muestra del enceguecimiento a lo impuesto a la periferia como progreso que siendo un horizonte demagógico vende a gusto el capitalismo como sinónimo de bienestar colocándose indistintamente en la subjetividad del sujeto generando una percepción sacra que se encarga de señalar con la propiedad suficiente los referentes de acción y movilización individual y social.

El común de las apariencias laborales sugiere una aproximación fundamentada en potenciar las características exhibidas por los escenarios socioculturales, económicos y éticos propios a quienes desde la base social definen el contexto latinoamericano, de manera que se sitúen en un nivel cualitativamente distinto a los modos de reproducción cultural capitalista. Es la búsqueda a través de la educación popular de un proceso radical de rechazo a la deshumanización del sujeto por la esfera económica pues en la que la medida de que todo es el valor de cambio, nacen expresiones en el conjunto social que cuando se asumen discrecionalmente el espíritu de un pueblo yace bajo el acto calculado de la racionalidad cuantificadora.

\section{En 3D. Recomendaciones sobre la Ceguera}

En este corto y emocionante recorrido como aspirantes a maestrantes, queremos agradecer a todos los docentes que hicieron de este proceso una grata aventura de crecimiento personal e intelectual que nos permitió ver no sólo con los ojos sino con el corazón y con todo nuestro ser. Llevamos escritas con tinta indeleble las palabras de Jaime Pineda en el seminario "Filosofía de la diversidad I”. “¿Cómo educar a otro sin renunciar a que el otro siga siendo otro?".(Pineda, 2012). Partiendo 
de esta frase dimos inicio a nuestra labor investigativa teniendo como eje nuestras autobiografías, haciendo uso de aquellas experiencias que nos han llevado a ser quien somos. A partir de ese análisis proponemos estas recomendaciones:

Mirar a los ojos de los otros que nos habitan, para poder reconocer su rostro aceptándolo tal cual es y no tratar de cambiarlo (Blanqueamiento de las personas).

Reconstruir nuestra historicidad para poder transformarla. Asimismo, develar a través de reflexiones en colectivo las relaciones de poder nocivas para nuestros territorios, y así aprender a ver de otra manera, usando nuestros otros sentidos.

Crear un nuevo lenguaje propio que nos represente y nos dé un verdadero sentido de pertenencia.

Cambiar el sistema autoritario y controlador en los procesos enseñanza aprendizaje por espacios de diálogo. Por lo cual invitamos a fortalecer un pensamiento crítico dejando de lado la competitividad, ya que esto nos puede alejar de nuestra experiencia y el aprendizaje que esta nos brinda, como docentes debemos tener en cuenta la integralidad de cada ser humano con el que trabajamos, por lo que se le hace relevante la importancia de que los docentes involucren de manera directa a psicología y la diversidad, teniendo en cuenta que tratamos con personas que piensan totalmente diferente y que carecen de afecto dentro de su grupo familiar.

Tener siempre presente nuestra humanidad, debemos pensar en sí mismos sin seguir modelos diseñados por otros, haciendo felices a los demás y dejando de lado nuestras propias opiniones. No somos mercancía; somos seres humanos con sentimientos y emociones.

Practicar la Educación como una relación de libertad y de aprendizaje mutuo y no como un instrumento bajo el cual se desarrolla unas relaciones de control y de opresión entre los interlocutores. Además debemos ver en nuestros estudiantes una visión no de producción donde se maneja una mercancía, de ninguna manera, porque no somos un producto individual, debemos considerar la relación con lo externo, para no caer en el consumismo educativo del Estado.

Desarrollar prácticas donde lo que impere no sea la fuerza ni el poder absoluto, y mucho menos usar técnicas como: gritos, regaños, castigos, silenciar, amenazas y prohibiciones, que humillen y minimicen al hombre, en este caso nuestros estudiantes, por el contrario fomentar el dialogo y los valores, especialmente la escucha y el respeto por el otro ser igual.

Interpretar la ceguera no sólo como una discapacidad, sino como otra forma de estar en el mundo. Dado que desde una educación para la diversidad no se deben seguir fortaleciendo estereotipos y significados que discriminan a los demás. Es por eso que desde las Cegueras de los maestros y los lenguajes del poder se quiere reconocer en la ceguera un estado de reflexión sobre la cotidianidad. Esta reflexión nos permitió descubrir que nuestras vidas son validadas sólo por las leyes del capitalismo y del poder del estado ejercido a través de las instituciones, en nuestro caso la educativa.

Reconocernos como sujetos históricos capaces de transformar la realidad a partir de la lectura de la propia vida. En otras palabras solo cuando seamos capaces de reflexionar sobre nuestras propias historias de vida, así como se ha hecho en este documento, se podrá tener la libertad de tomar decisiones sólidas y propias para construir una vida real, sin factores externos $u$ apariencias que controlen y decidan por nosotros. 


\section{Bibliografía}

\section{Fuentes}

Biografía de Henry Ford. En: http://www.biografiasyvidas.com/biografia/f/ford_henry.htm. (Recuperado en enero del 2013).

Bourdieu, Pierre. (S.f) Los tres estados del capital cultural. Disponible en: http://sociologiac.net/biblio/Bourdieu-LosTresEstadosdelCapitalCultural.pdf. (Recuperado en 31 de octubre del 2011).

Cañón, Óscar. (2008). Las huellas del sujeto en narrativas construccionistas (Bogotá). Revista diversita-Perspectivas en psicología, 04 (2), 245-257.

Castro Bueno, Fabio. Historia Oral (2004): Historias de vida e historias barriales. Bogotá, D.C: Colectivo de historia oral.

Córdoba Calvo, Erneyda Maritza. (2012). Autobiografía. Cauca: Universidad de Manizales.

Díaz Gómez, Álvaro (2012). Sobre la Subjetividad. Módulo Subjetividades. Manizales, Colombia: Universidad de Manizales.

Foucault, Michael. (1983). El sujeto y el poder. En: http://transdisciplinariedaduj.files. wordpress.com/2010/09/foucault-michel-elsujeto-y-el-poder.pdf. (Recuperado en 5 de febrero del 2013)

Freire, Paulo (S.f). Pedagogía del oprimido. En: http://www.servicioskoinonia.org/biblioteca/ general/FreirePedagogiadelOprimido.pdf. (Recuperado en 16 de diciembre de 2012)

Freire, Paulo. (1969). La educación como práctica de la libertad. México. Siglo Veintiuno editores. Redición. Módulo Subjetividades.

Fromm, Erich. (2006). Miedo a la libertad. En: http://www.enxarxa.com/biblioteca/ FROMM\%20EI\%20Miedo\%20A\%20La\%20 Libertad.pdf. (Recuperado en 5 de marzo del 2013).

García Márquez, Gabriel. (1978).Cien años de soledad. Editorial Andes

González González, Miguel Alberto. (2010). Umbrales de indolencia. Educación sombría y justicia indiferente. Manizales, Colombia: Editorial Universidad de Manizales. Manizales.

González González, Miguel Alberto. (2011). El extrañamiento del otro .Módulo Filosofía de la diversidad I. Manizales, Colombia: Universidad de Manizales.
González Monteagudo, José (2 de marzo de 2013). Seminario de migraciones, diversidad cultural e identidades cambiantes: retos para escuelas y comunidades. Maestría en Educación desde la Diversidad. Universidad de Manizales. Manizales.

Guarín Jurado, Germán. (2004). Razones para la racionalidad en horizonte de complejidad. Módulo modernidad crítica: fundamentos epistémico-metodológicos. Manizales, Colombia: Universidad de Manizales.

Guarín Jurado, Germán. (2011). Modernidad positiva. Módulo modernidad crítica: fundamentos epistémico-metodológicos. Manizales, Colombia: Universidad de Manizales.

Hernández Pulgarín, Gregorio (2011). Identidad, diferenciación social y capitalismo. Módulo de Antropología. Universidad de Manizales. Manizales.

Hernández Pulgarín, Gregorio. \& Carreño, María Teresa (2011). Globalización y Culturas Globales. Módulo Cultura Global Vs. Multiculturalidad. Universidad de Manizales. Manizales.

Mosquera Erazo, Pilar Magally. (2012). Autobiografía. Cauca: Universidad de Manizales

Nelly Erazo, Valencia. (2012). Autobiografía. Cauca: Universidad de Manizales.

Pierre, Jean. (2004) Investigación cualitativa. Colombia: Editorial Rudecolombia.

Pineda, Jaime (2012).Seminario Filosofía de la Diversidad I. Maestría desde de la Diversidad. Universidad de Manizales. Manizales.

Restrepo, Oscar Arturo. (2012). Autobiografía. Cauca: Universidad de Manizales.

Sabogal Londoño, Yeisit Veronica. (2012). Autobiografía. Cauca: Universidad de Manizales.

Sacén Fernando (2006). Pensar la identidad con Heidegger. En: http://www.Idiogenes. buap.mx/revistas/12/74.pdf. (Recuperado en 30 de mayo del 2012).

Saramago, José. (1995). Ensayo sobre la ceguera. Editorial Camino, S.A., Lisboa. En:http://web.seccoahuila.gob.mx/biblioweb/upload/Saramago, \%20Jose $\% 20$ $\% 20$ Ensayo $\% 20$ sobre $\% 201 a \% 20$ ceguera.pdf. (Recuperado en 28 de mayo del 2012.) 
Torres, Lissett. Ensayo sobre la ceguera de José Saramago: Representación de la Política y la Educación. En: http://www. otrocielo.com/tesis55.pdf. (Recuperado en 28 de mayo del 2012).

Zemelman, Hugo. (S, f). Pensar teórico y pensar epistémico: Los retos de las ciencias sociales latinoamericanas. En: http://www. ipecal.edu.mx/Biblioteca/Documentos/Documento7.pdf (Recuperado en septiembre del 2011)

Zygmunt, Bauman. (2003). Modernidad liquida. En: http://www.oei.org.ar/edumedia/pdfs/ T04_Docu5_\%20ModerndadLiquida_Bauman.pdf. (Recuperada en 31 de octubre del 2011)

\section{Referencias}

Aguirre, Lucia Alicia. (2011). Desigualdades, racismo cultural y diferencia colonial. En: http://www.desigualdades.net/bilder/publisten/WPLuciaAguerreOnline.pdf (Recuperado en junio 19 del 2013).

Andrés, Eugenio. \& Díez, José $M^{a}$. (2009). Patologías organizativas. Capital Humano. En:http://www.toptenhrs.com/Archivos/Descargas/CEGUERA032_s_Patologias $\% 20$ organiz_228.pdf. (Recuperado en 30 de mayo del 2012)

Backman Sepúlveda, Carolina Britt. (2008). Fotógrafos ciegos: percepción en la invidencia y la desmitificación de la pureza visual. En: http://catarina.udlap.mx/u_dl_a/tales/ documentos/lhu/backman_s_cb/portada. html (Recuperado en 10 de mayo de 2013).

De Paz Abril, Desiderio. (2004) "Prácticas escolares y socialización: La escuela como comunidad". Universidad Autónoma de Barcelona. En: http://www.tdx.cat/ bitstream/handle/10803/5123/dpa1de1. pdf?sequence=1. (Recuperado en 17 de junio del 2013).

Delgado, Carolina. (2006). Análisis del testimonio como fuente oral: género y memoria. Universidad de Salamanca. En: http://halshs.archives-ouvertes.fr/docs/00/10/40/16/ PDF/Delgado_Sahagun.pdf (Recuperado en 31 de julio del 2012).

Díaz Gómez, Álvaro \& González Rey, Fernando. (2005). Subjetividad: Una perspectiva histórico cultural. Conversación con el psicólogo cubano Fernando González Rey. En: http://redalyc.uaemex.mx/redalyc/src/inicio/
ArtPdfRed.jsp?iCve=64740311. (Recuperado en 19 de julio del 2012)

Diderot, Denis. (2002). Carta sobre los ciegos seguido de Cartas sobre los sordomudos. En: http://www.fundaciononce.es/ SiteCollectionDocuments/Publicaciones/ Carta sobreCiegos Carta\%20sobreSordomudos_fpd.pdf. ( Recuperado en 25 de enero del 2013)

Doin, German (Productor). (2012). La educación prohibida. [Video]. En: http://www. educacionprohibida.com. (Recuperado en 4 de marzo del 2013)

Fernández,_José \& Ulloa Jorge. ¿Profesores ciegos o estudiantes invisibles? En: http:// www.ts.ucr.ac.cr/binarios/tendencias/revco-tendencias-11-13.pdf._(Recuperado en 14 de septiembre del 2012).

García, J. Valdez, J. \& Gonzales, J (2009). La oftalmología en la obra poética de Jorge Luis Borges (II). En: http://scielo.isciii.es/ scielo. php? pid $=$ S0365669120090009000 09\&script=sci_arttext. (Recuperado en 15 de octubre del 2012)

Ghiso, Alfredo. (2000). Potenciando la Diversidad. (Diálogo de saberes, una práctica hermenéutica colectiva). En: http://bibliotecadigital.conevyt.org.mx/colecciones/ documentos/potenciando_diversidad.pdf. (Recuperado en 19 de agosto del 2012)

González González, Miguel Alberto. (2009). Horizontes humanos. Límites y paisajes. Manizales: Universidad de Manizales.

González González, Miguel Alberto. (2012). Desafíos de la universidad. Miradas plurales. Carpe Diem. Madrid: Editorial académica española.

Plano, Cecilia \& Querzoli Roberto (2003). La entrevista en la historia de vida. Observatorio Memoria y Prácticas Sociales en Derechos Humanos. En: http://observatoriomemoria.unq.edu.ar/publicaciones/entrevista. pdf. (Recuperado en 3 de agosto del 2012)

Quevedo, Amalia. (1992) La ceguera según Aristóteles. En: http://dspace.unav.es/ dspace/bitstream/10171/2331/1/04.Amalia\%20Quevedo,\%20La\%20ceguera $\% 20$ seg\%C3\%BAn\%20Arist\%C3\%B3teles.pdf. (Recuperado en 15 de mayo del 2012)

Reyes, Judith (1985). En torno a Paulo Freire: Aspectos filosóficos de su pensamiento y aportes a la reflexión de raíz Latinoame- 
ricana. Pontificia Universidad Católica de Chile. En: http://www.servicioskoinonia.org/ biblioteca/general/TesisFreire.pdf. (Recuperado en 13 de julio del 12)

Romano, Vicente. (2007). Intoxicación lingüística. Uso perverso de la lengua. En: http:// www.rebelion.org/docs/71900.pdf. (Recuperado en 3 de junio del 2013).

Zemelman, Hugo. (1995). Determinismos y Alternativas en las Ciencias Sociales de
América Latina. En: http://www.pedagogica. edu.co/storage/folios/articulos/fol12_04arti. pdf. (Recuperado en 15 de mayo del 2012)

Zemelman, Hugo. (1998). El conocimiento como desafío posible. En: http://www. amsafe.org.ar/formacion/images/2012ConcursoNormales/Eje 3/El_conocimiento_como_desafio_posible-Zemelman.pdf. (Recuperado en 24 de marzo del 2013). 